\title{
Macroeconomic uncertainty: measurement and impact on the Spanish economy
}

María Gil, Javier J.Pérez and Alberto Urtasun

This article characterises the level of uncertainty in the Spanish economy. Various indicators are analysed, distinguishing their source: financial market volatility, degree of disagreement between agents on the economic situation and economic policy uncertainty.

Aggregate uncertainty in the Spanish economy increased in 2016, although it remained at levels below the average for the $2008-2013$ recession.

The changes in uncertainty captured by financial indicators are shown to have a higher impact on economic activity, and particularly on investment.

Finally, it is illustrated how a significant part of the macroeconomic effect of the heightened uncertainty in the past year originated outside the Spanish economy. 


\section{MACROECONOMIC UNCERTAINTY: MEASUREMENT AND IMPACT ON THE SPANISH ECONOMY}

The authors of this article are María Gil, Javier J. Pérez and Alberto Urtasun, of the Associate Directorate General Economics and Research.

This article characterises the level of uncertainty in the Spanish economy. Various indicators are analysed, distinguishing their source: financial market volatility, degree of disagreement between agents on the economic situation and economic policy uncertainty.

Aggregate uncertainty in the Spanish economy increased in 2016, although it remained at levels below the average for the 2008-2013 recession.

The changes in uncertainty captured by financial indicators are shown to have a higher impact on economic activity, and particularly on investment.

Finally, it is illustrated how a significant part of the macroeconomic effect of the heightened uncertainty in the past year originated outside the Spanish economy.

Introduction

As for most of last year, global economic activity in early 2017 was set against a backdrop of high uncertainty largely associated with geopolitical events, such as the results of the referenda in Italy in December (on the reform of the Constitution) and particularly in the United Kingdom in June (on leaving the EU, the so-called Brexit), and the victory of Donald Trump in the US presidential elections. Other factors, such as the persistence of the migrant crisis and the European security problems, the Middle East tensions, the slowdown of some emerging economies and the doubts over the course the various initiatives for fuller euro area integration may finally take, may have also contributed to raising the uncertainty perceived by economic agents. Against this background, the second half of last year saw downward revisions of the world growth outlook by several international institutions. On the domestic front, some analysts associated the interim nature of the political situation during most of 2016, or the current government's parliamentary minority, with a possible heightening of uncertainty over the course of Spanish economic policy. From a longer time perspective, various analyses have argued that the weakness with which the global economy has exited the financial crisis could be explained largely by the situation of higher uncertainty than in the past. ${ }^{2}$

Economic agents always act in a setting of uncertainty. Households, firms and governments have to take decisions to spend or invest. To do so, they make certain assumptions on the future behaviour of certain variables and assign (subjectively or objectively) probability to the various states of nature, insofar as these can be identified. Furthermore, in the current environment of globalisation, in which economies are strongly integrated owing to trade flows and movements of people and capital, domestic agents' decisions are influenced by domestic and cross-border factors alike. This is particularly so in the euro area countries, because many economic policies (particularly monetary policy) are common to various countries.

The studies on how uncertainty affects economic activity find that marked increases in uncertainty may unfavourably affect agents' decisions and hence the economy as a whole. There are various channels through which this may occur, particularly through effects on household consumption and saving decisions, or on firms' investment and hiring decisions.

1 This article summarises the main ideas and results reported in Gil, Pérez and Urtasun (2017)

2 See, for example, IMF (2012) or Haddow and Hare (2013). 
Since uncertainty is not observable, it is not easy to determine quantitatively or qualitatively to what extent it has increased in the most recent period, whether it has done so above certain past average levels, or whether that increase may affect performance (particularly that of the Spanish economy) more than what would result from external or inherent factors of the current phase of the economic cycle. ${ }^{3}$

Against this background, this article provides a considerable number of indicators to proxy the level of and changes in the economic uncertainty in the Spanish economy. Based on the behaviour of different indicators over time, a number of empirical regularities are identified. In particular, the behaviour of indicators is analysed in recessions and booms, and in electoral periods. Finally, estimates are provided of the average responses of certain key macroeconomic aggregates (GDP, and private consumption and investment) to unexpected increases in uncertainty indicators, distinguishing between domestic and cross-border ones.

Measurement of uncertainty: methodology and indicators
Economists use alternative empirical measures to quantify uncertainty. It is common, for example, to use the volatility observed in stock markets [Bloom (2009)], the cross-sectional dispersion of expert or business survey expectations [Bachmann, Elstner and Sims (2013)], the frequency of press references to terms relating to economic policy uncertainty [Baker, Bloom and Davis (2015)], the common variation of unforecastable components in econometric models [Jurado, Ludvigson and $\mathrm{Ng}$ (2015)] or forecasting errors calculated using real-time statistical models [Scotti (2016)]

In this study we selected a number of measures and divided them into the following groups $^{4}$ (see Table 1): a) indicators based on financial market data (group 1); b) indicators based on the degree of disagreement between economic agents regarding the economic situation and outlook (group 2); and c) indicators of uncertainty about economic policy and about the political situation of the country (group 3).

Regarding the individual indicators listed in Table 1, the financial measures have the advantage of being readily available in real time and directly comparable across countries. Regarding the second group of indicators, i.e. measures of disagreement between economic agents, their use is based on the assumption that an increase in uncertainty would, under certain conditions, have the effect of broadening the possible range of future results and therefore this would be manifest in a higher dispersion of the expectations of analysts, consumers and firms. Pursuing this idea, we calculated the degree of disagreement using, firstly, discrepancies between the analysts contributing to the FUNCAS forecast panel ${ }^{5}$; and, secondly, the responses of consumers and firms to the opinion-based surveys conducted monthly by the European Commission. ${ }^{6}$ Finally, the measures in group 3 relate to genuinely political expectations and opinions, to the degree of political fragmentation of the (national or regional) parliament, ${ }^{7}$ to "political risk"

3 In line with the literature, this article defines "uncertainty" as the lack of certainty as to the future performance of economic activity or as to the future course of economic policy, so there is some overlap between the concepts of "risk" and "subjective uncertainty" (uncertainty according to Knight). In the former, the probabilities of the possible outcomes are known (a probability distribution can be determined), but not the outcome itself. For example, with a coin toss there is a $50 \%$ probability that the outcome will be heads or tails. By contrast, the latter refers to a situation in which the possible states of nature are not delimited and cannot be assigned probabilities. For a more detailed discussion, see Guerrón Quintana (2012) or Rossi, Sekhposyan and Soupre (2016).

4 Along these lines, see Haddow and Hare (2013) and the references cited therein.

5 Available in real-time on the FUNCAS website: https://www.funcas.es/Indicadores/Indicadores.aspx?ld=1.

6 Using the methodologies of Bachmann, Elstner and Sims (2013) and of Dovern, Fritsche and Slacalek (2012).

7 Herfindahl-Hirschman index. See footnote (e) to Table 2 for a description of how it is constructed. 


\begin{tabular}{|c|c|c|c|}
\hline & Sample starts in: & Frequency & $\begin{array}{c}\text { Correlation with } \\
\text { principal } \\
\text { component (b) }\end{array}$ \\
\hline \multicolumn{4}{|l|}{1 FINANCIAL MARKETS } \\
\hline IBEX-35 volatility & March-1997 & Daily & 0.59 \\
\hline IBEX-35 volatility index (c) & December-1999 & Monthly & 0.59 \\
\hline$\$ / €$ exchange rate volatility index (c) & December-1999 & Monthly & 0.38 \\
\hline Brent price volatility index (c) & December-1999 & Monthly & -0.05 \\
\hline 10 year bond price volatility index (c) & December-1999 & Monthly & 0.62 \\
\hline \multicolumn{4}{|l|}{2 DISAGREEMENT } \\
\hline Disagreement about GDP forecasts* & January-1999 & Every two months & 0.71 \\
\hline Disagreement about private consumption forecasts* & January-1999 & Every two months & 0.70 \\
\hline Disagreement about capital goods investment forecasts* & January-1999 & Every two months & 0.74 \\
\hline Uncertainty about unemployment outlook over next 12 months* & June-1986 & Monthly & 0.47 \\
\hline Uncertainty about industrial order books & January-1993 & Monthly & 0.48 \\
\hline Uncertainty about industrial production expectations* & January-1993 & Monthly & 0.41 \\
\hline \multicolumn{4}{|l|}{3 ECONOMIC POLICY UNCERTAINTY } \\
\hline Current political situation indicator & January-1996 & Monthly & 0.50 \\
\hline Political expectations indicator & January-1996 & Monthly & 0.49 \\
\hline Political risk indicator & January-1984 & Monthly & 0.54 \\
\hline National parliamentary fragmentation index (d) & January-1995 & Monthly & - \\
\hline Economic policy uncertainty indicator (EPU) & January-2001 & Monthly & 0.19 \\
\hline Disagreement about budget deficit forecasts* & January-1999 & Every two months: & 0.44 \\
\hline
\end{tabular}

SOURCES: Bloomberg, IESE, FUNCAS forecast panel, European Commission, CIS barometer, PRS Goup, and BdE calculations. See Gil, Pérez and Urtasun 2017) for more details.

a Indicators marked with an asterisk were prepared by the BdE.

b The first principal component of the set of all the indicators included in the table is calculated and the correlation of this principal component with each of the indicators used for the calculation is shown.

c These four indices are the components of the I3E economic uncertainty indicator prepared by IESE.

d See the definition of this index in Table 2 (footnote e). This indicator is not included in the principal components calculation because it shows little variation over time.

(weighted index of factors such as government stability, socio-economic conditions and the quality of institutions) and variables proxying the degree of economic policy uncertainty. Regarding the latter, Table 1 includes two indicators. First, the well-known index of Baker, Bloom and Davis (2015) [Economic Policy Uncertainty Index (EPU)], which is based on searches for keywords in the press, counting each month the number of newspaper articles which simultaneously contain terms having to do with economy, economic policy and uncertainty. Second, an indicator of the degree of disagreement in the budget deficit forecasts of a set of analysts. ${ }^{8}$

The measures of uncertainty listed in Table 1 capture not only genuinely domestic elements, but also the direct or indirect effect derived from changes in uncertainty in other European countries or factors of a global nature. This is illustrated in Chart 1, which shows the behaviour throughout 2016 of three selected indicators (one from each group in Table 1) for the Spanish economy and their respective European equivalents. Chart 1.1 shows a stock market volatility index which is higher in January-February and June 2016 than in December

8 Also based on the FUNCAS forecast panel. 
1 STOCK MARKET VOLATILITY (a)

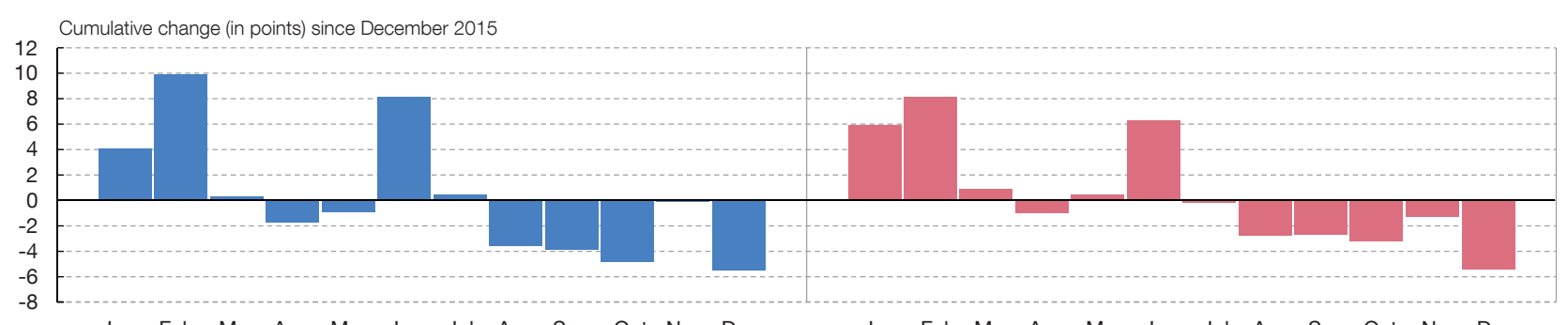

Jan Feb Mar Apr May Jun Jul Aug Sep Oct Nov Dec Jan Feb Mar Apr May Jun Jul Aug Sep Oct Nov Dec

IBEX-35 EUROSTOXX-50

2 UNCERTAINTY ABOUT INDUSTRIAL ORDER BOOKS (b)

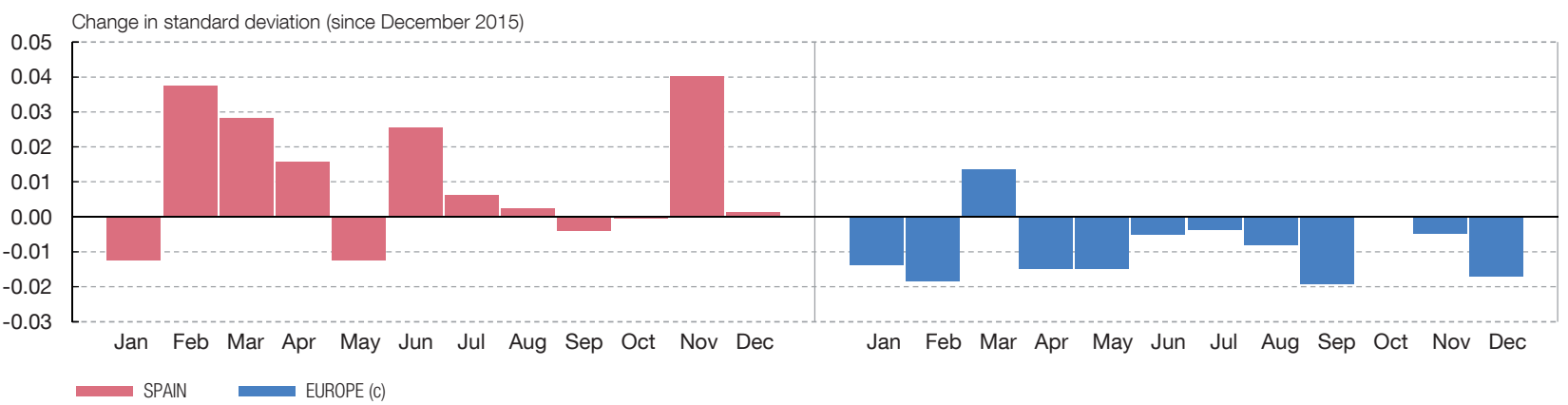

3 ECONOMIC POLICY UNCERTAINTY INDEX

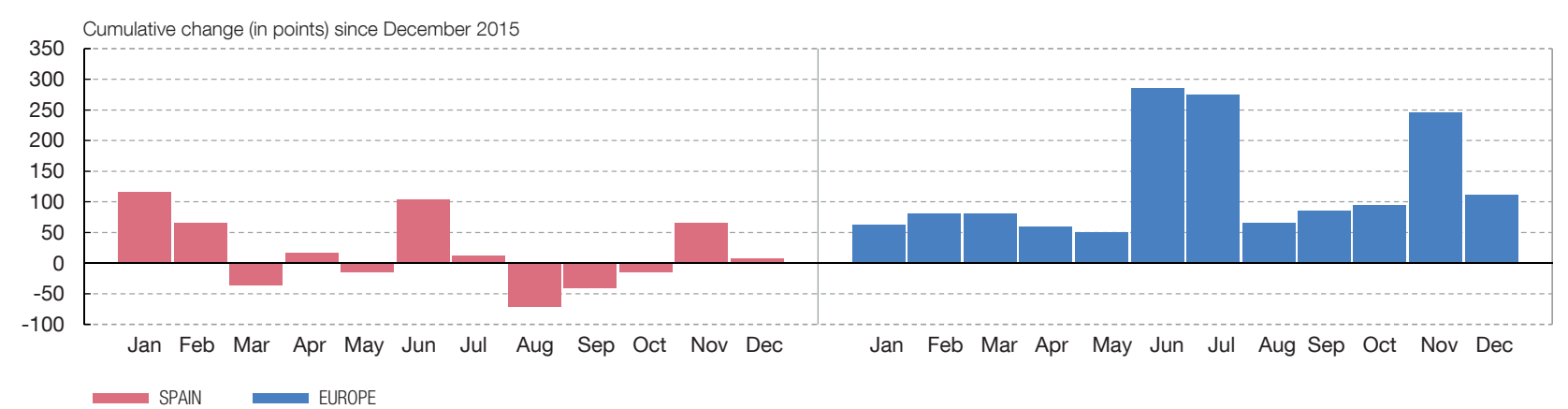

SOURCES: Bloomberg, European Commission and www.policyuncertainty.com.

a IBEX-35 and EUROSTOXX-50 volatility indices taken from Bloomberg.

b Calculated using data from European Commission consumer and business confidence surveys.

c Average for Germany, France, Italy and the United Kingdom.

d Indicator taken from www.policyuncertainty.com.

2015, both in Spain and in Europe. Although for Spain some of the increase may be associated with the aforementioned elections in December 2015 and the end of June 2016, other more global factors were in play in those months, particularly the doubts over some emerging economies in early 2016 and the Brexit referendum in June. Both the "disagreement" indicator selected (see Chart 1.2) and the economic policy indicator (EPU, see Chart 1.3) show a somewhat more different behaviour among the indices for Spain and Europe. In the case of the former, uncertainty over industrial order books increased and remained unchanged during the whole year for Spain, whereas it declined in Europe, albeit 
1 SYNTHETIC INDICATOR OF ECONOMIC UNCERTAINTY

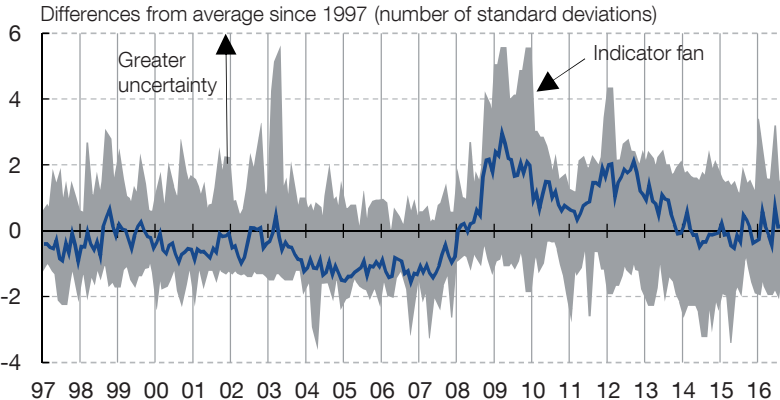

3 SYNTHETIC INDICATOR OF DISAGREEMENT

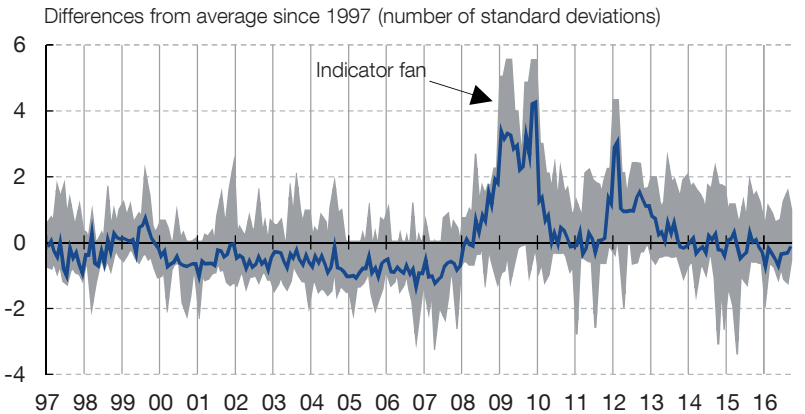

2 SYNTHETIC INDICATOR OF FINANCIAL MARKETS

Differences from average since 1997 (number of standard deviations)

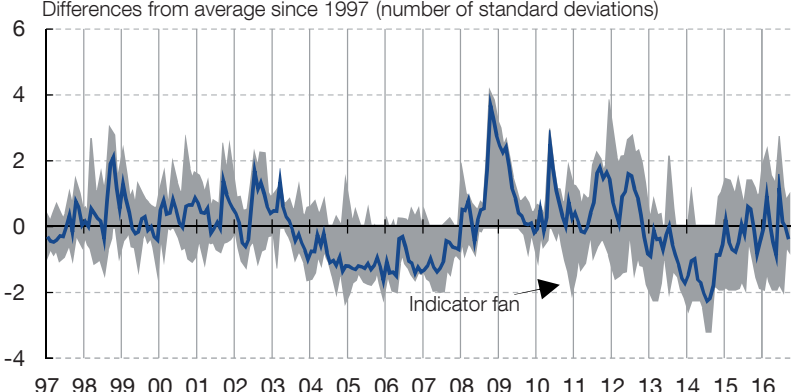

4 SYNTHETIC INDICATOR OF ECONOMIC POLICY UNCERTAINTY

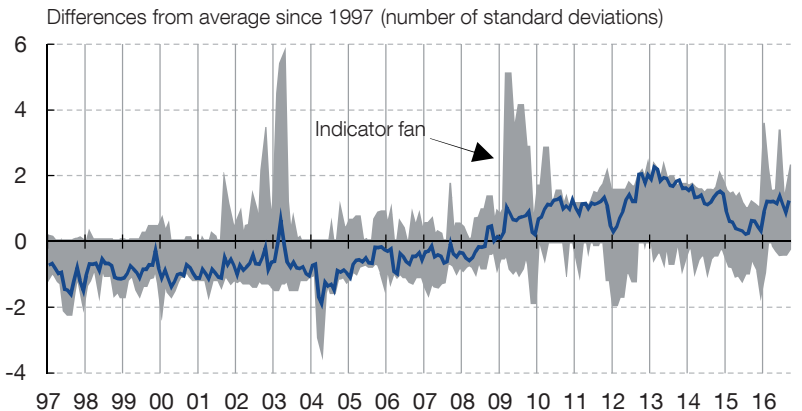

PRINCIPAL COMPONENT

SOURCE: Banco de España

a For the uncertainty indicators used and the groups, see Table 1.

showing very little variability in both cases. With respect to the EPU (see Chart 1.3), the changes in the indicator for Spain reflect increases in January-February, June and November 2016 with respect to 2015, although it ended 2016 at a similar level to that of the previous year, while the index for Europe reflects a specific increase in uncertainty throughout the whole year, largely dominated by the behaviour of this index in the United Kingdom.

The analysis set out in this article adopts a non-committal stance regarding the relative significance of the measures set out in Table 1, and so combines information from all of them to obtain a synthetic indicator. This allows a picture which is more complete and subject to lower volatility of the uncertainty in the Spanish economy than that which can be provided by the individual indicators taken one by one. In this respect, Chart 2.1 shows the first principal component extracted from the indicators listed in Table $1,{ }^{9}$ along with their range (shaded area) for the time period 1997-2016. Focusing on the most recent data, the chart indicates that the aggregate uncertainty in the Spanish economy increased slightly in 2016 and was highly variable, although in any event standing at significantly lower levels than those between 2008 and 2013. This synthetic indicator is constructed

9 Principal components analysis is a statistical technique used to condense information or reduce the dimensionality of sets of variables, so that the least possible amount of Information is lost. This method generates a new group of variables (the principal components) which are linear combinations of the original variables and, in addition, are mutually independent. To calculate the principal components we used the recursive method of Stock and Watson (2002), which allows all the sample information available in the total data to be used (from January 1997). 

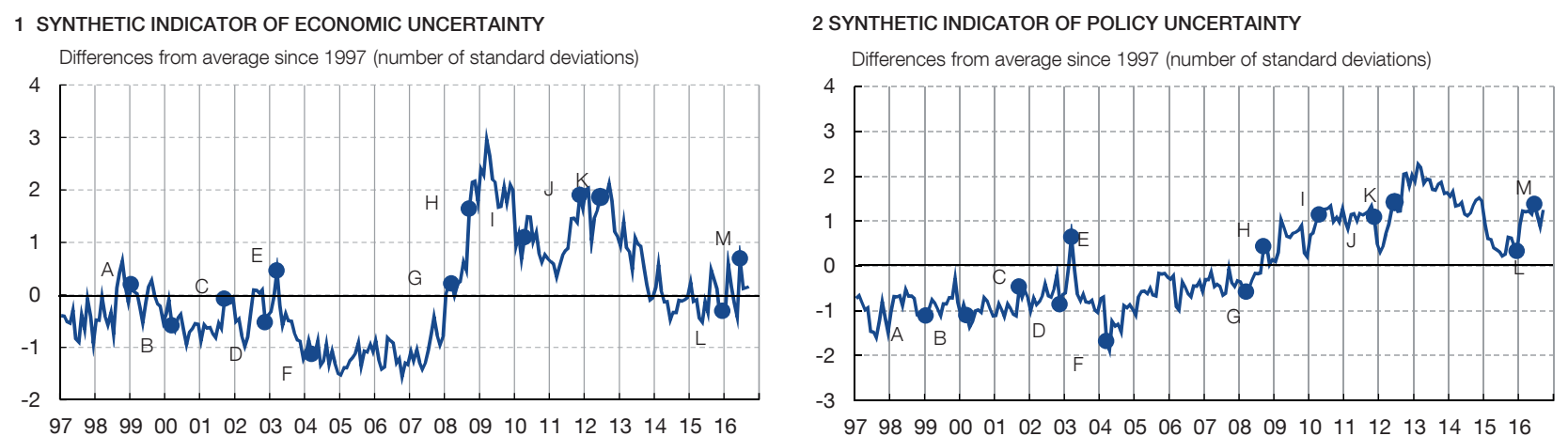

Selection of prominent events

\begin{tabular}{ll}
\hline A January 1999 & Creation of the EMU \\
\hline B March 2000 & General elections in Spain \\
\hline C September 2001 & 11-S terrorist atacks \\
\hline D November 2002 & Sinking of the Prestige \\
\hline E March 2003 & Invasion of Iraq \\
\hline F March 2004 & 11-M terrorist attacks and general elections in Spain \\
\hline G March 2008 & Bear Sterns bail-out and general elections in Spain \\
\hline H September 2008 & Lehman Brothers bankruptcy \\
\hline I April 2010 & Greece requests financial aid \\
\hline J November 2011 & General elections in Spain \\
\hline K June 2012 & Financial aid for Spain \\
\hline L December 2015 & General elections in Spain \\
\hline M June 2016 & United Kingdom referendum (Brexit) and general elections in Spain
\end{tabular}

SOURCE: Banco de España.

from heterogeneous sources of uncertainty, as reflected by the wide range represented by the shaded area of Chart 2.1. To give a more granular idea of this heterogeneity, summary measures by indicator group are given in the other panels of this chart. Thus Charts 2.2 and 2.3 show the main components of groups 1 and 2 ("financial markets" and "economic disagreement"), whose behaviour in the most recent period is similar to that of the composite index of all indicators. Chart 2.4 plots the measure of economic policy uncertainty (the first principal component of the group 3 indicators in Table 1), which indicates how this is estimated to have increased in 2016 to similar levels to those of the period 2008-2011, standing above the historical average and only lower than the levels reached in the period 2012-2013.

Chart 3 examines whether the synthetic indicator of uncertainty and the partial indicator of economic policy uncertainty showed significant changes at the time of events which, a priori, could be associated with changes in uncertainty, such as the terrorist attacks of 11 September 2001 in the United States, the Lehman Brothers bankruptcy in September 2008 or the request for financial aid by Greece in April 2010. There is generally a high coincidence between these events and the synthetic indicators considered, either contemporaneously or with a lag. Also, in some cases, the measures of aggregate uncertainty and of policy uncertainty seem to respond differently, as might be expected. For example, in the case of the requests by Greece for a bail-out or by Spain for financial support in 2012 (points I and K, respectively, in Chart 3), the aggregate uncertainty 


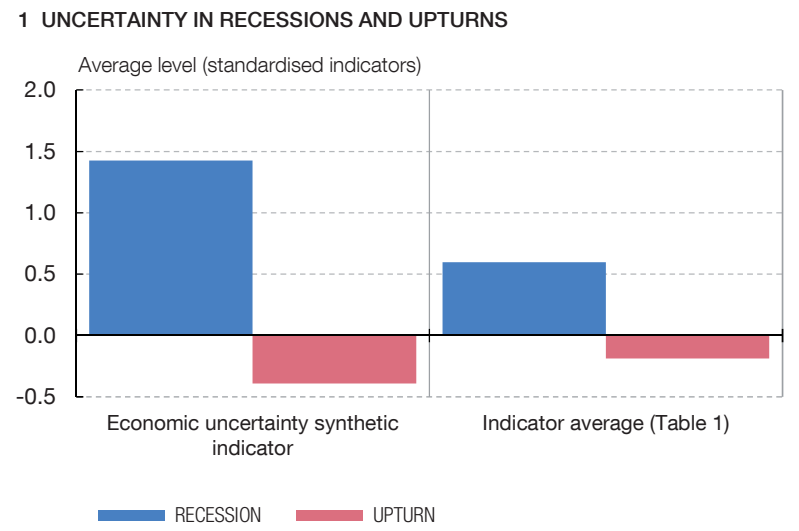

2 UNCERTAINTY AND UNEMPLOYMENT RATE

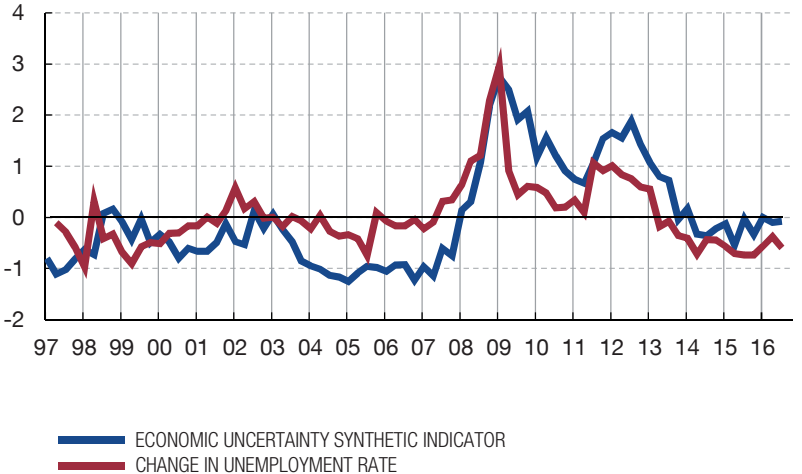

SOURCE: Banco de España, based on the indicators in Table 1.

a The recession periods were obtained from the dating proposed by the committee of experts of the Spanish Economic Association (for the period 1997-2016).

decreased in the following months, as would be expected, while the level of economic policy uncertainty increased or held steady, possibly reflecting the deadlock until the various actions to be taken in the EU interventions were defined.

Chart 4.1, as well as Charts 2 and 3, shows visually that uncertainty tends to be higher in recessions than in economic upturns, in line with the findings reported for other countries. ${ }^{10}$ In step with this, the synthetic indicator behaves very similarly to the change in the unemployment rate (see Chart 4.2), which is a customary measure of uncertainty in the models for determining household consumption and saving. Further, the high uncertainty in recessions is clearly illustrated by certain measures of disagreement between analysts, such as those in Chart 5, which shows the course since January 2006 of the average forecasts of GDP, private consumption and investment, and budget deficit, derived from the FUNCAS forecast panel, along with the range of the forecasts made by the analysts on that panel. ${ }^{11}$ The chart shows how the forecast range widens in recessions.

Finally, to isolate events of a national (idiosyncratic) nature, some evidence of the behaviour of uncertainty indicators in electoral periods is presented. Elections may contribute to reducing or raising uncertainty, depending on agents' expectations as to their outcome and on whether or not a definite economic policy stance is expected which will be applied as a result of the election outcome. Along these same lines, the pre- and post-electoral periods may also be linked to increases or decreases in uncertainty. Moreover, the uncertainty surrounding elections may be influenced by the degree of parliamentary fragmentation. Table 2 portrays the impact of general elections on uncertainty, measured using the four indices described above. According to the tentative evidence presented in the table, aggregate economic uncertainty tends to be higher in those quarters in which elections are held (see first row of results in the table), although the coefficient is estimated with little precision and is not statistically different from zero. The aggregate result masks various effects among the different measures, which are in keeping with what would be expected.

10 Among others, see, for example, Bloom (2014) for the United States, Moore (2016) for Australia, and the references cited in these studies.

11 On the basis of which the disagreement indicators discussed above were constructed. 


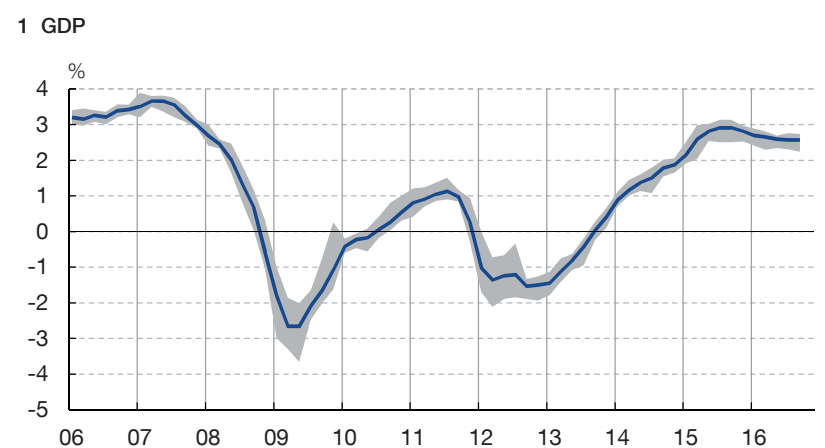

3 PRIVATE CONSUMPTION

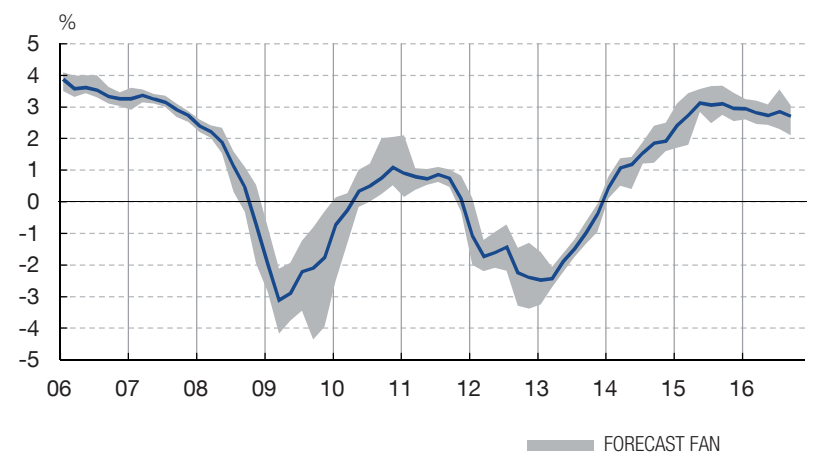

SOURCE: FUNCAS forecast panels.
2 GOVERNMENT DEFICIT

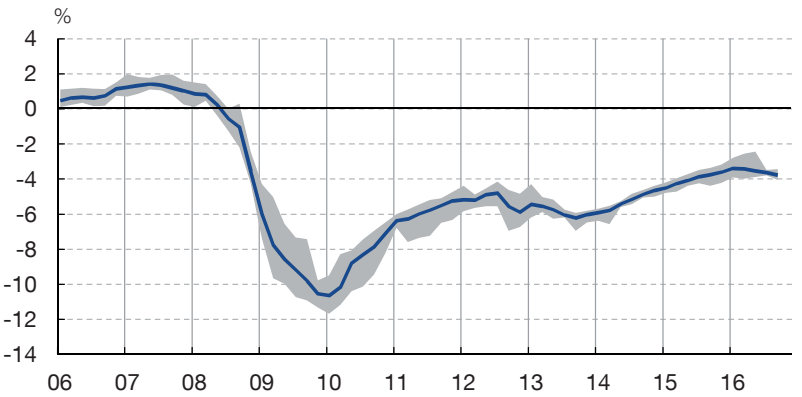

4 CAPITAL GOODS INVESTMENT

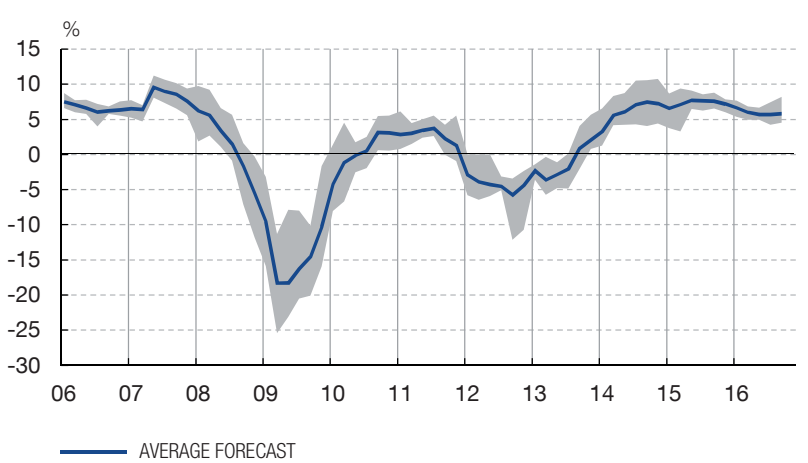

UNCERTAINTY AND ELECTION PERIODS (a)

Elections

(b)
Pre-election period Post-election period

(c) (d)

d)

Parliamentary fragmentation index

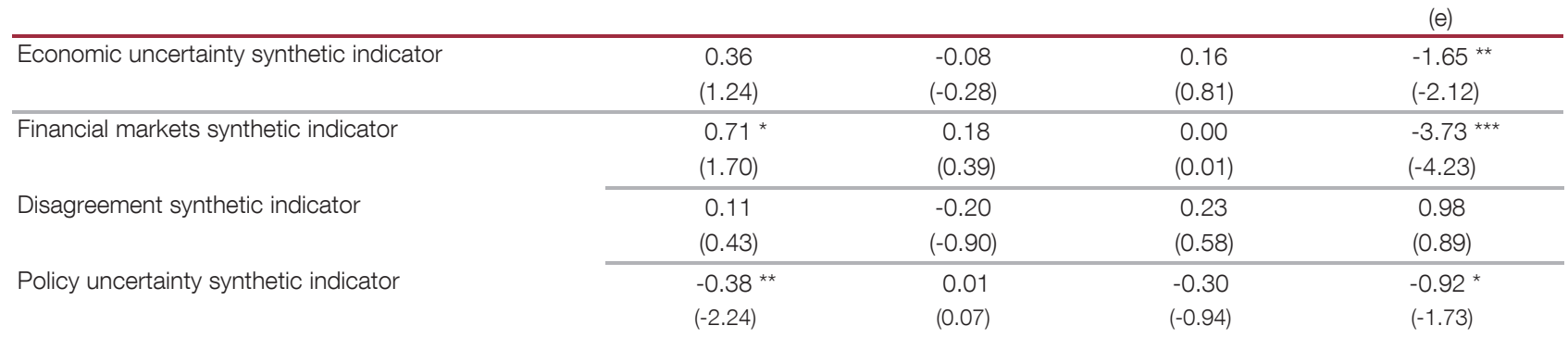

SOURCE: Banco de España.

a Regression models where the dependent variable is the measure of uncertainty. The lags in all the internal uncertainty indicators, external uncertainty measures, GDP and inflation are added as control variables in all the models. Quarterly data: 1997 Q3 - 2016 Q3.

${ }^{*}{ }^{* *}$ and ${ }^{* \star \star}$ indicate statistical significance at $10 \%, 5 \%$ and $1 \%$, respectively. T statistics are in brackets.

b The value of this variable is 1 if national elections are held in the quarter and 0 otherwise.

c Definida como la variable de elecciones adelantada un trimestre.

d Defined as the elections variable brought forward by one quarter.

e National Parliamentary fragmentation index (based on the Herfindahl-Hirschman index). An increase indicates lower fragmentation. This index measures the degree of concentration or fragmentation as the sum of the power quotas (squared) of the political parties that have representatives in Parliament, where "power quota" is defined as the seats obtained by each party as a percentage of total seats. The maximum value of this index is 1 , representing a scenario where one single party would obtain all the seats. As the index value decreases, political fragmentation increases.

In fact, the impact on the financial measure of uncertainty is positive and significant, that on the disagreement indicator is also positive (although not significantly different from zero), while the holding of elections tends to reduce uncertainty as to the future course of economic policy. Regarding the variable measuring national parliamentary fragmentation, the results show that an increase in it is generally associated with higher uncertainty. 
Analysis of the impact of uncertainty on Spain's economy
This section includes estimates of the impact of increased uncertainty on the Spanish economy. ${ }^{12}$ The estimation method used is based on vector auto-regressive (VAR) models, into which are incorporated the summary measures of uncertainty described earlier, based on the indicators of financial market volatility, degree of disagreement among analysts and economic policy uncertainty, as well as various macroeconomic aggregates, such as GDP, private consumption and investment in capital goods. Additional control variables are also included, such as the Spanish sovereign debt spread over the German Bund and a price index, ${ }^{13}$ to take into account the possible impact of financial and nominal variables on the different uncertainty indicators. ${ }^{14}$ The analysis also takes into consideration the effect of the uncertainty arising from the external environment, particularly the EU, enabling us to isolate the effects of national idiosyncratic shocks. ${ }^{15}$

Chart 6 displays the main results of the empirical exercises conducted. Chart 6.1 contains GDP responses to unexpected increases in the three aforementioned measures proxying the different sources of uncertainty, ${ }^{16}$ explicitly controlling the uncertainty captured by the indicators of external uncertainty. The chart shows that uncertainty shocks cause GDP decreases, in line with the three alternative indicators. The uncertainty measure with the largest (from the viewpoint of statistical significance) and most persistent effect is that captured by the financial markets measure. Also, Charts 6.2 to 6.4 depict again, for each indicator, the GDP response to unexpected uncertainty increases, but they supplement that shown in Chart 6.1 by adding the resulting responses in the event that external sources of uncertainty are not explicitly taken into account. ${ }^{17}$ It can be seen in the charts that the GDP response in this second case is also negative, but it is more persistent and significant from a statistical viewpoint, which shows that uncertainty measures partially reflect external shocks and that these are significant for the dynamics of the Spanish economy.

Finally, Charts 6.5 and 6.6. show the responses of private consumption and capital goods investment to the three summary measures of uncertainty. The qualitative impacts are similar to those discussed in the preceding paragraph, i.e. an unexpected increase in uncertainty gives rise to a decline in private consumption and investment. Also, the responses of these variables are quantitatively more significant than those of GDP, with the negative response of investment being particularly noteworthy, as might be expected. Thus, against a backdrop of increased uncertainty, households would be able to allocate a greater percentage of their income to precautionary saving, thereby drawing off resources that would have been used for consumption under normal circumstances, which would affect demand in the economy. Similarly, in these circumstances, firms may delay new investment and hiring, within a framework where planning the costs and profits associated with such projects is more complex. The foregoing patterns of behaviour would entail consequences not only for economic demand, but also for supply, insofar as the decrease in investment spending, even if temporary, may also affect the economy's future supply capacity.

12 Specialised studies available for different countries tend to find a negative relationship between increases in economic uncertainty (measured on the basis of some of the indicators discussed in this article or others) and economic activity (see the studies cited throughout this article and Estrada, Garrote, Valdeolivas and Vallés (2014), among others). The evidence available for Spain is scant: see BBVA (2016), Fernández Villaverde and López Salido (2016) or Posada, Urtasun and González Mínguez (2014).

$13 \mathrm{CPI}$ excluding unprocessed food and energy, regulated prices and VAT; seasonally adjusted.

14 For details on the specification of the models used, see Gil, Pérez and Urtasun (2017).

15 As mentioned in the preceding section, these are measures for the major EU countries, similar to those shown for Spain in Table 1. For more details, see Gil, Pérez and Urtasun (2017).

16 Shocks equivalent in size to a standard deviation.

17 For this purpose, the same VAR model discussed previously is estimated, but excluding exogenous control variables relating to external uncertainty (measures for the EU). 
1 GDP RESPONSE TO UNCERTAINTY: ALTERNATIVE MEASURES

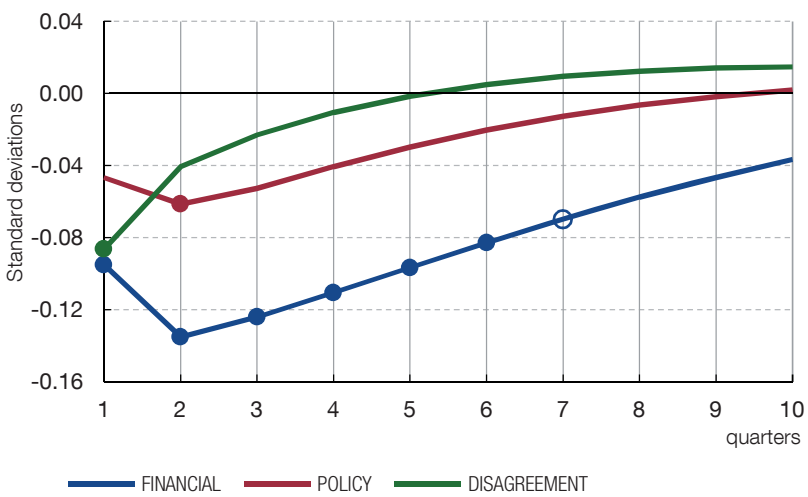

3 GDP RESPONSE TO UNCERTAINTY MEASURED BY DISAGREEMENT

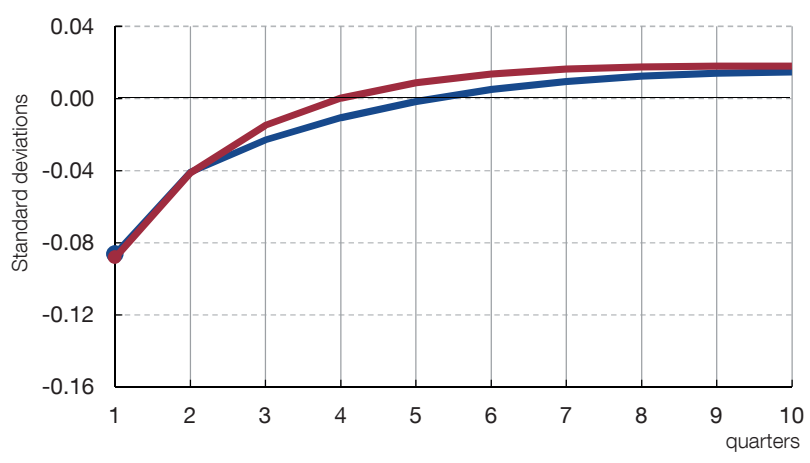

BASELINE SPECIFICATION

EXCLUDING EXTERNAL UNCERTAINTY VARIABLES

5 CONSUMPTION RESPONSE TO UNCERTAINTY

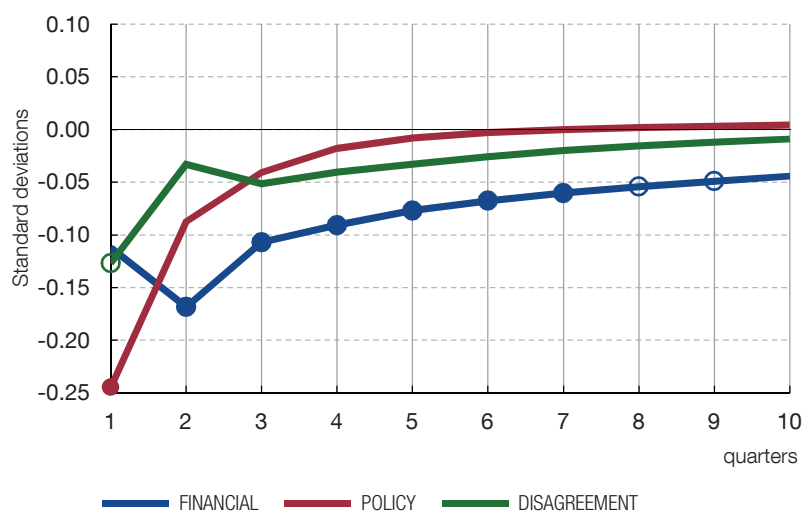

2 GDP RESPONSE TO THE FINANCIAL MEASURE OF UNCERTAINTY

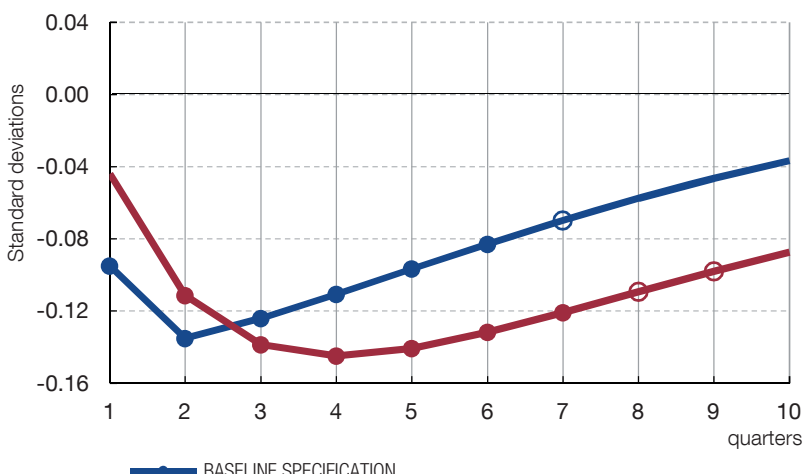

EXCLUDING EXTERNAL UNCERTAINTY VARIABLES

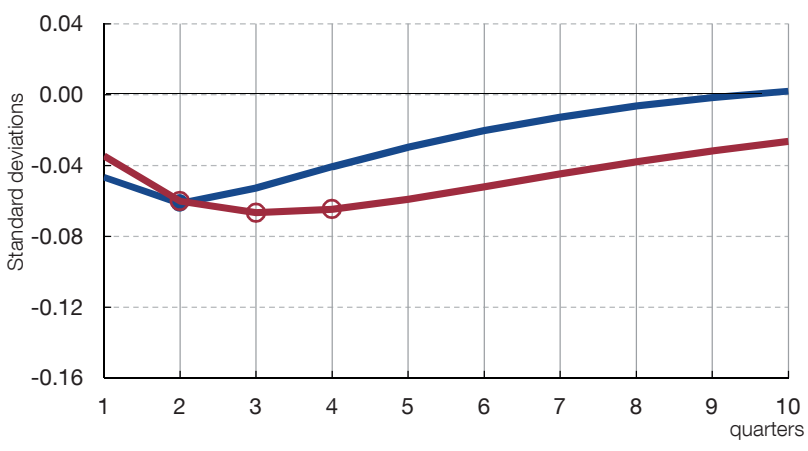

BASELINE SPECIFICATION

EXCLUDING EXTERNAL UNCERTAINTY VARIABLES
6 CAPITAL GOODS INVESTMENT RESPONSE TO UNCERTAINTY

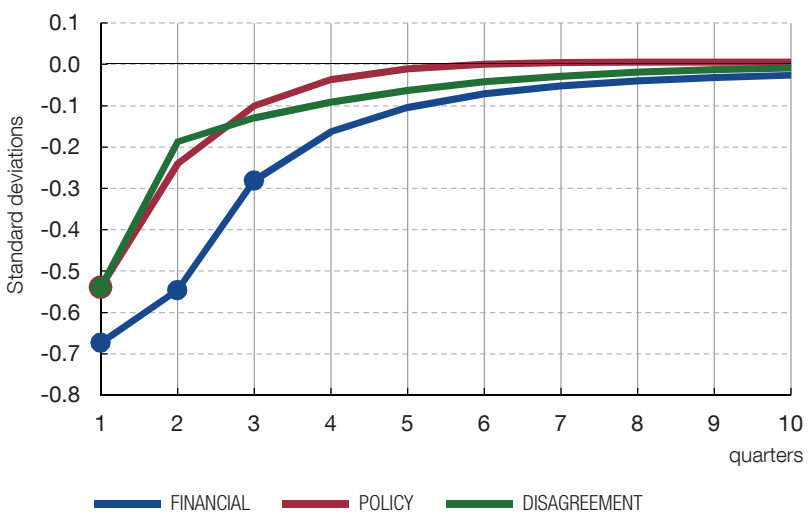

SOURCE: Banco de España.

a The VAR model includes as endogenous variables the uncertainty measured by the synthetic indicators of financial markets, disagreement and economic policy uncertainty, GDP/consumption/investment, the Spanish sovereign debt spread over the German Bund and a price index; and itincludes as exogenous variables Eurostoxx-50 volatility, the EPU for the EU as a whole and a synthetic indicator of European uncertainty (calculated in a manner similar to that used for Spain's synthetic indices).

Indicates statistical significance at $5 \%$

Indicates statistical significance at10\%. 
1 DIFFERENCES IN AVERAGE GROWTH IN 2016 WITH RESPECT TO A SCENARIO WHERE UNCERTAINTY WOULD HAVE REMAINED AT THE LEVEL RECORDED IN 2015 Q4 (a)

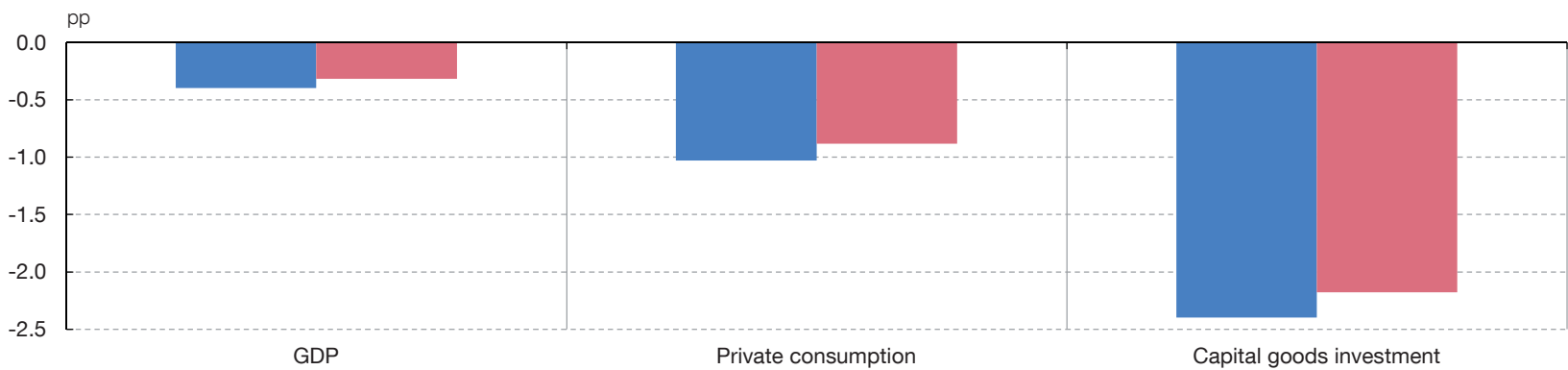

SCENARIO 1: DIFFERENTIAL IMPACT OF THE INCREASE IN UNCERTAINTY IN 2016

SCENARIO 2: DIFFERENTIAL IMPACT OF THE INCREASE IN EXTERNAL UNCERTAINTY IN 2016

2 CHANGE IN SYNTHETIC INDICATORS IN 2016 (b)

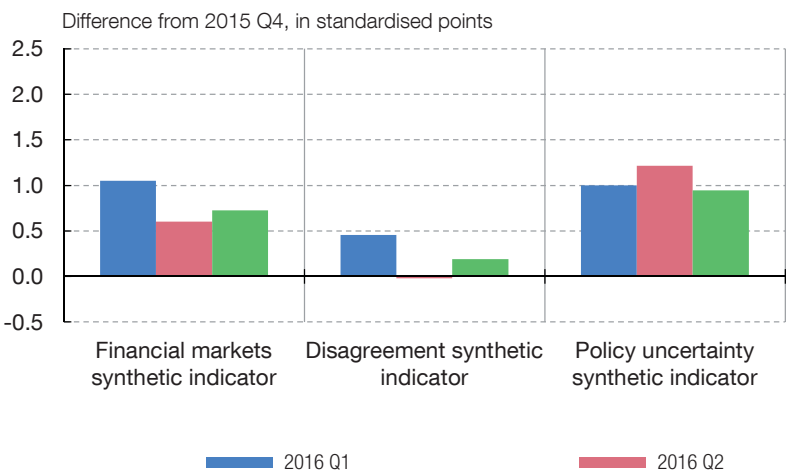

3 CHANGE IN EXTERNAL UNCERTAINTY IN 2016 (b)

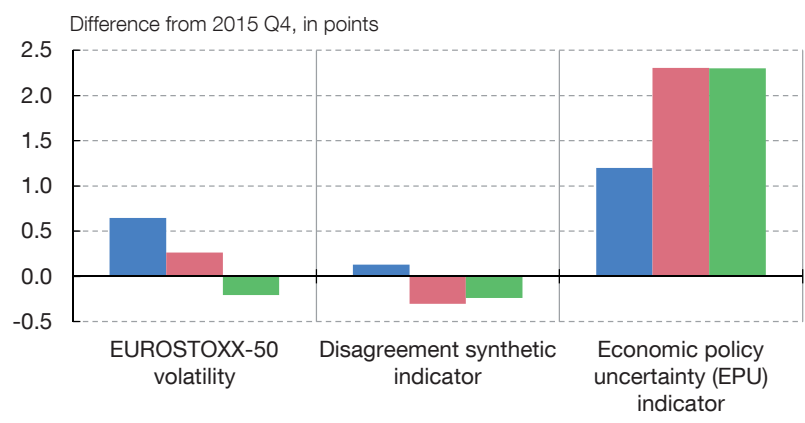

2016 Q3

SOURCE: Banco de España.

a The scenarios are obtained using the differences resulting from making forecasts for 2016 with VAR models similar to that used in the exercises shown in Chart 6, under different assumptions relating to the uncertainty variables (national and European). Under Scenario 1, the bars represent the difference between the GDP/consumption/investment forecasts obtained with the VAR model baseline specification assuming that the values observed in2016 are known for all the uncertainty variables, and the forecasts based on the same model, but assuming that the uncertainty variables (national and European) remained in 2016 at the values observed in 2015 Q4. Under Scenario 2, the differences between the same baseline scenario and the model forecast are calculated, only the European indicators being subject to the same assumption (that the values of 2015 Q4 are maintained). Therefore, Scenario 1 includes the total impact of the change in uncertainty in 2016 on GDP, consumption and investment, alternatively, while Scenario 2 represents the impact of the increase inexternal sources of uncertainty.

b The bars represent the difference between each indicator in each quarter and their level in 2015 Q4.

The simulations discussed in the foregoing paragraphs are based on hypothetical responses calculated using the estimated models. However, these models may also be used to illustrate the possible macroeconomic impact of the change in uncertainty in 2016. Thus, the models are used in Chart 7 to calculate the differential effects on the growth of GDP and private consumption and investment under two alternative scenarios. Scenario 1 of Chart 7.1 shows the calculation of the difference between a hypothetical situation where it is assumed that the synthetic and European uncertainty indicators would have recorded the levels effectively seen in 2016 and another where it is assumed that in 2016 those indicators would have remained at the levels observed in 2015 Q4. In this case, therefore, the total effect arising from the increase in uncertainty (see Charts 7.2 and 7.3) would have been to reduce growth in GDP, consumption and investment by approximately $0.4 \mathrm{pp}, 1 \mathrm{pp}$ and $2.4 \mathrm{pp}$, respectively, in accordance with the counterfactual simulations conducted with the model. However, most of this total effect could be attributed to the change in external sources of uncertainty. This is what is shown in scenario 2 of Chart 7.1, where the effect arising from these sources is isolated so that the differential effect between the two 
scenarios, which would approximate the genuine domestic effect, is found to be lower growth of GDP, consumption and investment of $0.1 \mathrm{pp}, 0.1 \mathrm{pp}$ and $0.2 \mathrm{pp}$, respectively. These figures, however, should be interpreted with caution and merely for illustrative purposes, since they are crucially dependent on the assumptions made when counterfactual scenarios are constructed, as well as on the use of a specific statistical tool.

\section{REFERENCES}

BANCO DE ESPAÑA 12 ANALYTICAL ARTICLES MACROECONOMIC UNCERTAINTY: MEASUREMENT AND IMPACT ON THE SPANISH ECONOMY
BACHMANN, R., S. ELSTNER and E. SIMS (2013). "Uncertainty and Economic Activity: Evidence from Business Survey Data", American Economic Journal: Macroeconomics, 5, pp. 217-24.

BAKER, S., N. BLOOM and S. DAVIS (2015). Measuring Economic Policy Uncertainty, NBER Working Paper No. 21633.

BBVA (2016), Box 1, "La incertidumbre sobre la política económica en España: medición e impacto", in the report Situación España. Primer trimestre de 2016.

BLOOM, N. (2014). "Fluctuations in Uncertainty", Journal of Economic Perspectives, 28, pp. 153-176.

- (2009). "The impact of uncertainty shocks", Econometrica, 77, pp. 623-685.

DOVERN J., U. FRISTCHE and J. SLACALEK (2012). "Disagreement among forecasters in G7 countries", Review of Economics and Statistics, 4, pp. 1,081-1,096.

ESTRADA, A., D. GARROTE, E. VALDEOLIVAS and J. VALLÉS (2014). Household debt and uncertainty: private consumption after the Great Recession, Working Paper 1415, Banco de España.

FERNÁNDEZ VILLAVERDE, J., and J. D. LÓPEZ SALIDO (2016). "Los costes de la incertidumbre política en España", post in the blog Nada es Gratis.

FMI (2012). World economic outlook: coping with high debt and sluggish growth, chapter 1, "Global Prospects and Policies", Box 1.3, "How Does Uncertainty Affect Economic Performance?", World Economic and Financial Surveys, October, pp. 56-60.

GIL, M., J. J. PÉREZ and A. URTASUN (2017). Measuring macroeconomic uncertainty and its effects: the case of Spain, Working Paper, Banco de España, forthcoming.

GUERRÓN-QUINTANA, P. A. (2012). "Risk and Uncertainty", Federal Reserve Bank of Philadelphia Business Review, 2012 Q1.

HADDOW, A., and C. HARE (2013). "Macroeconomic uncertainty: what is it, how can we measure it and why does it matter?", Bank of England Quarterly Bulletin, 2013 Q2.

JURADO, K., S. C. LUDVIGSON and S. NG (2015). "Measuring uncertainty", The American Economic Review, 105, pp. $1177-1216$

MOORE, A. (2016). "Measuring economic uncertainty and its effects", Reserve Bank of Australia, Research Discussion Paper 2016-01.

POSADA, D., A. URTASUN and J. M. GONZÁLEZ MÍNGUEZ (2014). "Un análisis del comportamiento reciente de la inversión en equipo y de sus determinantes", Boletín Económico, June, Banco de España, pp. 41-50.

ROSSI, B., T. SEKHPOSYAN and M. SOUPRE (2016). Understanding the sources of macroeconomic uncertainty, ICREA-Universitat Pompeu Fabra, May.

SCOTTI, C. (2016). "Surprise and uncertainty indexes: real-time aggregation of real-activity macro surprises", Journal of Monetary Economics, 82, pp. 1-19.

STOCK, J. H., and M. W. WATSON (2002). "Forecasting Using Principal Components from a Large Number of Predictors", Journal of the American Statistical Association, 97, pp. 1,167-1,179. 